\title{
Capstone Project Evaluation - Towards a Student-Centred Approach
}

\author{
Cheryl Schramm and Adrian D. C. Chan \\ Carleton University \\ schramm@sce.carleton.ca, adcchan@sce.carleton.ca
}

\begin{abstract}
Capstone projects present a particular challenge to assessment as compared to individual course work. Projects unfold over a year, culminating in a final report, begging the question of (balancing the) assessment of process over product. Projects across an individual department, let alone across the engineering faculty, can differ in content, the balance of depth versus breadth, the balance of research versus application, the balance of design versus implementation, and size of teams. One approach to managing this diversity is the use of broadly interpreted categories and no explicit weighted marking scheme, with the final grade determined by consensus in a department-wide meeting, held privately from the students. While flexibility and the authority of the supervising faculty member is acknowledged and maintained in this approach, the needs of the students are not necessarily best served in this approach.

The movement toward learning outcomes, including the CEAB Graduate Attribute Criteria, is providing a wellunderstood and documented language for established indicators. This paper presents the results of an effort this year to incorporate $C E A B$ graduate attributes into a system of marking rubrics. The goal is to better serve the needs of students with an assessment strategy that is based on explicit expectations and transparency, one which includes all deliverables, and yet still accommodates for diversity in project experiences. The paper will present the compound assessment instrument developed and used on select project teams, as well as the feedback of the students involved in the experience. The work done this year is seen as preliminary and the intent is to invite feedback to move towards broaden the adoption of the assessment instruments within our community.
\end{abstract}

Keywords: Capstone Project, Assessment Instrument, Graduate Attributes, Engineering Design Process.

\section{INTRODUCTION}

This paper presents the development and implementation of an assessment instrument for engineering capstone projects. The principal impetus for this effort is a desire to improve the learning experience and outcomes of the student, rather than solely for grade accountability. The objective is to provide students with guidance and feedback on the engineering design process, as well as increased clarity on the learning outcomes of the capstone project and transparency in the grading process. In doing so, we are adopting philosophies of current pedagogical theories, including: 1) a belief that assessment must include evaluation on and feedback on the learning process, not simply the final product, and 2) the responsibility as instructors to provide timely, constructive formative [6] feedback to improve the learning experience of the students. Putting the student's learning at the centre imposes a need for established public criteria that in turn fosters a dialogue between supervisor and student about understanding the assessment, and involvement and agency in subsequent learning.

In addition to a student-centred approach, the assessment strategy will also incorporate the recent work by the Canadian Engineering Accreditation Board (CEAB) in standardized graduate attributes [2].

Both motivations - adopting a student-centred approach and integrating the $\mathrm{CEAB}$ graduate attributes - translate into an effort to transform the assessment for the capstone project from solely generating a reliable grade into one that serves both formative and summative assessment needs, with an emphasis on the formative aspects. The task is challenging; its context requiring consistent and accurate evaluation over many assessors of both complex and subjective criteria.

\subsection{Context}

In Carleton University's Department of Systems \& Computer Engineering, capstone projects teams typically have between two and four students, which are supervised by one or two faculty members. Topics vary because the department has five different programs: Computer Systems (CSE), Electrical (EE), Biomedical and Electrical (BEE), Software (SE) and Communications (CE) Engineering. Project groups may comprise of students from different programs. In the past academic year (2012/13), 21 faculty 
members supervised 41 projects across 117 students: CSE (24), EE (31), BEE (20), SE(29) and CE (13).

With the variety of topics also come diverse workloads comprising various weights for the different stages of the engineering design cycle (problem identification, proposed solution, implementation and test/evaluation). Over the course of the academic year, project groups submit five department-wide deliverables: 1) project proposal, 2) progress report, 3) oral presentation, 4) poster presentation, and 5) final report. The first two deliverables do not have any required assessment; any grading or feedback depends on the supervisor(s). The latter three deliverables are assessed jointly by the supervisor(s) and an appointed second reader. Students receive a grade for the oral presentation and the poster fair; as such, students expect that these marks "count". Yet, from the vantage of the students, there is no stated path explicitly linking these deliverables to their final grade. The grading by the supervisor(s) and second reader is used to guide the overall grading of projects. Projects are graded during a departmental meeting that is explained to students as a consensus in professional judgment. A final project grade is assigned; however, a grade for the final report is not explicitly provided. The contribution of the final report is typically heavily weighted in the final grade. Feedback on the latter three deliverables depends on the supervisor(s).

\subsection{Problem Definition}

There are two tensions to resolve in formulating a project assessment strategy, mirroring nicely two branches of assessment literature: 1) summative assessment and 2) formative assessment, now known more formally as Assessment for Learning (AFL). AFL includes "any actions taken by the teacher to gather information about student learning. It becomes formative in nature when assessment information is used to adjust instruction to help students achieve learning goals" [7]. The purpose in AFL is not solely to score a culminating product, but to inform and adjust the remaining teaching and learning.

In the capstone project, the underlying process is the engineering design process: problem identification, proposed solution, implementation, and test/evaluation. One criteria of import for our assessment strategy will be to reinforce learning of this engineering process throughout the project's duration.

\subsection{Solutions Considered}

The most straightforward plan would be to create a rubric straight from the twelve graduate attributes. Romkey [5] shows such a curriculum mapping in developing a set of rubrics which were "developed outside of a specific assessment context, but can be used as a "starting point" ... [for ] specific assessment pieces". Their rubric set contained a different rubric for the proposal, the oral presentation and the final report. We argue that, beyond the size and complexity of such a rubric, while the graduate attributes are all required or applicable for a student in the capstone project, they are not necessarily what should be assessed directly. For example, a knowledge base for engineering will be used in the project, but should be assessed in other courses. Also, assessment of each of the attributes can be difficult as they do not manifest themselves in mutually exclusive ways during the project.

We seek a solution that can be mapped to the CEAB graduate attributes but one that evaluates a student's practice of the engineering process which, we claim, is a key learning outcome of the capstone project. Davis [3] takes a similar approach in distilling the learning outcomes for capstone projects to four performance areas: 1) personal capacity (exercising engineering skills), 2) team processes, 3) solution requirements and 4) solution assets. Davis [3] develops a series of rubrics based on these performance areas, demonstrating how they can be used for both summative and formative purposes.

Davis's work is used in [4] in which the four performance areas are shown to align with ABET criteria [1]. The project is modeled as a progression of three phases: 1) Problem Scoping, 2) Concept Generation, and 3) Solution Realization. "Development assessments are administered midway throughout each phase while the resulting Solution Assets assessments are administered toward the end of each phase". The mid-phase assessments provide formative feedback, while the end-of-phase product assessments provide the summative assessment data. We share a similar view of the three phases of a capstone project, but argue that projects often iterate more than they progress, with students re-visiting and improving each phase throughout the academic year. We also seek to unify the formative and summative assessments into one instrument; this benefits the student by receiving assessments in an assessment framework that is consistent throughout the project.

This paper presents the results of a case study, in which the focus was on the experience of the authors during the development and trial use, to discover and gain in-depth understanding of the challenges with the objective of pursuing a wider adoption in the next year.

\subsection{Significance of the Results}

The assessment instruments were piloted on a set of four projects and refined through the year, based on feedback and experiences. Our current assessment instrument is what is presented in this paper. We are ready for wider exposure and feedback.

The assessment instruments are fully documented and posted publicly at [8] as part of a project to improve the information provided to students 


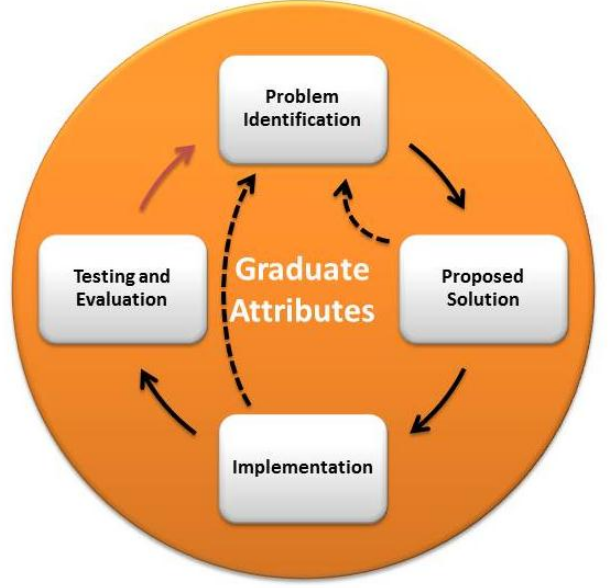

Fig. 1. Overlaying the Engineering Process on the CEAB Graduate Attributes

\section{COMPOUND ASSESSMENT INSTRUMENT}

\subsection{Overview}

Our objective is to establish a stable yet versatile assessment instrument that combines simplicity and consistency of use for all project deliverables with a structure that is grounded in the established CEAB graduate attributes but puts the emphasis on the engineering process.

The first task was to overlay the traditional engineering design cycle, with the twelve $\mathrm{CEAB}$ graduate attributes (Figure 1). Due to time constraints, it was unlikely that students would complete a design cycle fully, iterating back to the problem identification stage; however, it was acknowledged that student would, and should, be revisiting previous design stages through the design process, which is reflected in the assessment system (e.g., problem identification is graded throughout the project). As a capstone project, students should be demonstrating these graduate attributes throughout the year. As noted previously, these graduate attributes will not manifest as mutually exclusive elements, nor will they all apply in all parts of a project. In addition, assessment of each and every individual graduate attribute during the capstone project can be cumbersome.

The second task was to extract out common elements of all deliverables, and conceptualize their representations of the twelve CEAB graduate attributes. Four assessment dimensions were identified: 1) Engineering Design, 2) Communication, 3) Professionalism, and 4) Individual and Team Work (Figure 2).

These four dimensions generally align with the twelve graduate attributes (Table 1). Engineering Design contains all four stages of the engineering design cycle (Figure 1); the weighting of each design stage will differ from each deliverable. Broadly speaking, the Engineering Design

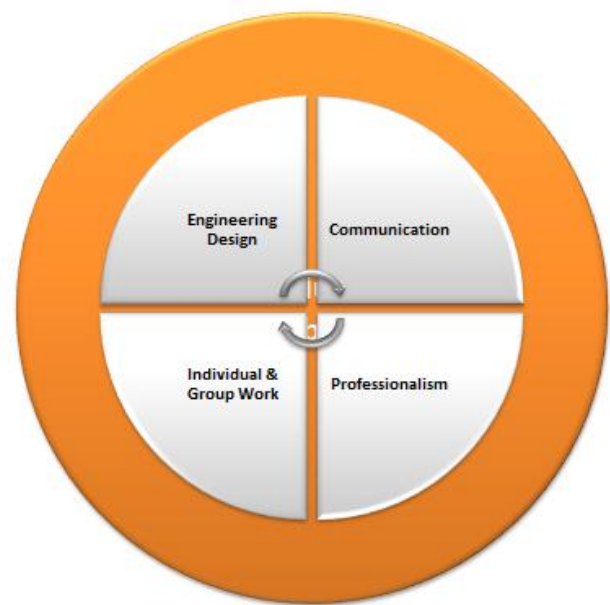

Fig. 2. Overlaying Four Dimensions on the CEAB Graduate Attributes

dimension comprises the "technical" CEAB graduate attributes. The dimensions of Communication and Individual and Team Work mostly align with the correspondingly named CEAB graduate attributes, whilst the Professionalism dimension includes the CEAB professionalism graduate attribute as well as impact of engineering on society and the environment, ethics and equity, economics and project management, life-long learning

Finally, to resolve the tension between a stable and consistent assessment instrument with the need for versatility and wide applicability, a compound assessment instrument was constructed. The compound assessment instrument consists of two coupled parts: 1) a rubric template containing a fixed, static structure, and 2) a marking scheme that assigns weights to each dimension appropriate to the current deliverable. The intent is to achieve consensus on the static structure of the template, but acknowledge the probability that the weights will be subject to change, perhaps year to year and maybe even from project to project.

The compound assessment instrument is presented in these two stages in the next two subsections. Table 2 presents the dimensions of assessment and their indicators of a rubric template that is applicable to all project deliverables. Table 3 shows how this generic template instrument is tailored through weightings for each individual project deliverables.

\subsection{Rubric Template}

All project deliverables comprise the four dimensions (Figure 2): Engineering Design, Communication, Professionalism, and Individual and Group Work. Engineering Design is further refined into the four engineering design stages (Figure 1): problem identification, proposed solution, implementation, and 
Table 1: Description of the dimensions that projects will be assessed on and the CEAB graduate attributes (GA) that they are primarily associated with.

\begin{tabular}{|l|l|l|}
\hline \multicolumn{1}{|c|}{ Dimension } & \multicolumn{1}{|c|}{ Description } & \multicolumn{1}{|c|}{ CEAB Graduate Attributes [2] } \\
\hline $\begin{array}{l}\text { Engineering } \\
\text { Design }\end{array}$ & $\begin{array}{l}\text { Engineering design refers to the design of an appropriate } \\
\text { solution for a "complex, open-ended engineering } \\
\text { problem" [8]. Engineering design requires a good } \\
\text { knowledge base for engineering, problem, analysis, } \\
\text { investigation, and appropriate use of engineering tools. }\end{array}$ & $\begin{array}{l}\text { GA1 A knowledge base for engineering } \\
\text { GA2 Problem analysis } \\
\text { GA3 Investigation } \\
\text { GA4 Design } \\
\text { GA5 Use of engineering tools }\end{array}$ \\
\hline $\begin{array}{l}\text { Communication } \\
\text { Skills }\end{array}$ & $\begin{array}{l}\text { Communications refers to the ability to read, write, } \\
\text { speak, and listen. This includes the ability to } \\
\text { communicate across different levels (e.g., with technical } \\
\text { experts, with the general public) and the across different } \\
\text { modalities (e.g., oral, written, schematics, diagrams, } \\
\text { graphs). }\end{array}$ & GA7 Communications skills \\
\hline Professionalism & $\begin{array}{l}\text { Professionalism refer to the "understanding of the roles } \\
\text { and responsibilities of the professional engineering in } \\
\text { society" [8] and the "appropriate attention to health and } \\
\text { safety, applicable standards, and economic, } \\
\text { environmental, cultural and societal considerations" [8]. } \\
\text { Projects must take into account the impact of engineering } \\
\text { on society and the environment. Appropriate project } \\
\text { management should be employed throughout. }\end{array}$ & $\begin{array}{l}\text { GA8 Professionalism } \\
\text { GA9 Impact of engineering on society } \\
\text { and the environment } \\
\text { GA10 Ethics and equity } \\
\text { GA11 Economics and project } \\
\text { GA12 Life-long learning }\end{array}$ \\
\hline $\begin{array}{l}\text { Individual and } \\
\text { Team Work }\end{array}$ & $\begin{array}{l}\text { Individual and team work refers to the "ability to work } \\
\text { effectively as a member and leader in teams" [8]. }\end{array}$ & GA6 Individual and team work \\
\hline
\end{tabular}

testing and evaluation. Collectively, these seven dimensions are explained in Table 2.

The actual rubric is generated from Table 2. A separate (small) rubric is formed for each of the seven dimensions, for a total of seven rubrics. The seven small rubrics could be presented as one large one, but we prefer to separate for a less onerous impression. Table 5 shows how the rows of each rubric derive from the indicators given for the dimension; the columns comprise a typical four levels of achievement: 1) Beginning, 2) Developing, 3) Accomplished, and 4) Exemplary. The number of labels for the achievements levels, or their names, can be adjusted to one's preference; for instance, we also provided an alternative wording of: 1) Needs Work, 2) Satisfactory, 3) Good, 4) Excellent.

\subsection{Marking Scheme}

The intent is to use the same assessment instrument over the course of the year for all deliverables. Using the same assessment instrument promotes familiarity, consistency, and predictability. From the marker's perspective, familiarity with the indicators allows marking to be more efficient and feedback to be more consistent. From the student's perspective, the repeated and familiar application of the same indicators highlights the permeation of skills across activities, emphasizes the continued importance of, and iteration through, the four stages of the engineering design process, and gives clear direction on where to improve upon for the next assessment. The challenge is to harmonize the grading of a progress report with an oral presentation. A weighted marking scheme is used.

Weights are used to re-balance the dimensions per deliverable. For example, compare the weights of Problem Identification (Table 3) for the project proposal $(40 \%)$, the oral presentation $(25 \%)$ and the final report $(10 \%)$. In the project proposal, Problem Identification is a key task; the oral presentation (mid-way through the year) is an opportunity to revise; for the final report, students should now fully understand the importance and skill in identifying the problem concisely and clearly through a final refinement. As a counter example, the weights of Communication do not vary linearly over the year; instead, the Communication dimension is consistently important for all written deliverables $(30 \%)$ but is weighted heavier in the oral presentation and poster fair $(50 \%)$ because the key purpose of these tasks is communication.

\subsection{Rubric-Marking Scheme Mapping}

The rubrics stand alone as a formative assessment instrument, a vehicle for providing descriptive feedback on the progress of the team. The marking scheme acts as the summative assessment instrument, providing a numeric grade.

As yet, we do not have a formulaic mapping from the qualitative rubric scorings to a quantitative value required 
Table 2: Dimensions that the project will be graded on, as well the indicators and their descriptions used in the grading.

\begin{tabular}{|c|c|c|c|}
\hline \multicolumn{2}{|c|}{ Dimension } & Indicator & Description \\
\hline \multirow[t]{11}{*}{$\begin{array}{l}\text { Engineering } \\
\text { Design }\end{array}$} & \multirow[t]{2}{*}{$\begin{array}{l}\text { Problem } \\
\text { Identification }\end{array}$} & $\begin{array}{l}\text { Context and } \\
\text { Motivation }\end{array}$ & $\begin{array}{l}\text { Project is placed in context of the current state-of-the-art. } \\
\text { Rationale for the project is credible and persuasive }\end{array}$ \\
\hline & & Clarity of Objective & $\begin{array}{l}\text { Objective of the project is readily identifiable, clear, focused, } \\
\text { and stated in a precise and concise manner. Scope of the } \\
\text { problem is well-defined and justified. }\end{array}$ \\
\hline & \multirow[t]{3}{*}{$\begin{array}{l}\text { Proposed } \\
\text { Solution }\end{array}$} & Feasible & $\begin{array}{l}\text { Solution is practical considering various constraints (e.g., time, } \\
\text { cost, complexity, resources). }\end{array}$ \\
\hline & & Informed & $\begin{array}{l}\text { Solution has evidence of merit (e.g., literature, preliminary } \\
\text { prototyping or testing) and addresses the problem. }\end{array}$ \\
\hline & & Creative & $\begin{array}{l}\text { Solution is elegant and appropriately engineered. Considers } \\
\text { multiple factors (e.g., technological, economic, social, } \\
\text { environmental, human). }\end{array}$ \\
\hline & \multirow[t]{3}{*}{ Implementation } & Functional & Implementation operates. It is robust, reliable, and accurate. \\
\hline & & Quality & $\begin{array}{l}\text { Implementation considers multiple factors (e.g., performance, } \\
\text { health/safety, usability, aesthetics, reusability, expandability, } \\
\text { and efficiency). }\end{array}$ \\
\hline & & Utility & $\begin{array}{l}\text { Implementation fulfills purpose or design intent. Provides } \\
\text { value. }\end{array}$ \\
\hline & \multirow[t]{3}{*}{$\begin{array}{l}\text { Testing and/or } \\
\text { Evaluation }\end{array}$} & Purposeful & $\begin{array}{l}\text { Objectives of testing and evaluation are readily identifiable, } \\
\text { clear, and focused. }\end{array}$ \\
\hline & & Methodical & $\begin{array}{l}\text { Procedures are well-planned (e.g., orderly, appropriate control } \\
\text { of variables). Testing and evaluation procedures are clear and } \\
\text { repeatable. }\end{array}$ \\
\hline & & Analytical & $\begin{array}{l}\text { Critical examination of results and observations is systematic, } \\
\text { reflective, and balanced. }\end{array}$ \\
\hline \multirow{3}{*}{\multicolumn{2}{|c|}{ Communication Skills }} & Credible & $\begin{array}{l}\text { Clear, concise, and organized. Appropriate technical and } \\
\text { formal tone and style. Understandable in both language } \\
\text { (grammar/spelling) and composition. }\end{array}$ \\
\hline & & Logical & $\begin{array}{l}\text { Good reasoning, including use of evidence. Communication is } \\
\text { cohesive and coherent. }\end{array}$ \\
\hline & & Convincing & Persuasive and engaging. Accessible, yet technically sound. \\
\hline \multirow{3}{*}{\multicolumn{2}{|c|}{ Professionalism }} & Responsible & Is intrinsically motivated and personally accountable. \\
\hline & & Conduct & $\begin{array}{l}\text { Acts with integrity. Is respectful and reliable. Is positive with } \\
\text { both supervisor and peers. Integrates health and safety within } \\
\text { project. }\end{array}$ \\
\hline & & Competence & $\begin{array}{l}\text { Work is a combination of excellence and efficiency. Values } \\
\text { continual learning and improvement. }\end{array}$ \\
\hline \multirow{3}{*}{\multicolumn{2}{|c|}{ Individual and Team Work }} & $\begin{array}{l}\text { Constructive and } \\
\text { Supportive }\end{array}$ & $\begin{array}{l}\text { Makes active and positive contributions. Demonstrates mutual } \\
\text { trust and respect. Is empathetic and helpful. Positive working } \\
\text { environment. }\end{array}$ \\
\hline & & Collaborative & $\begin{array}{l}\text { Works together with others towards common shared goals (not } \\
\text { just divide-and-conquer). Individuals form a cohesive team. }\end{array}$ \\
\hline & & Organized & $\begin{array}{l}\text { Commonly understood organizational structure. Clarity in } \\
\text { goals and direction. Good communication and understanding } \\
\text { among team members. }\end{array}$ \\
\hline
\end{tabular}

as input for the marking scheme. During this pilot, assessors mapped from the rubric to a grade on their own intuitive methods. Grades were consistent between assessors, indicating that the assessment instrument is reliable; however, more rigour is needed.

\section{RESULTS and DISCUSSION}

Table 2 is a simplification of the original rubric template. In the first term of the project, the original rubric was larger and was essentially a direct mapping of all $\mathrm{CEAB}$ attributes to the rubric indicators. The marking 
Table 3: Dimensions that the project will be graded on, as well the indicators and their descriptions used in the grading.

\begin{tabular}{|c|c|c|c|c|c|c|c|c|c|}
\hline & 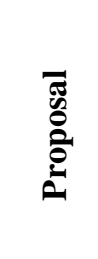 & 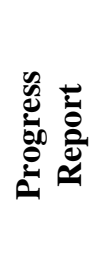 & 氙 & 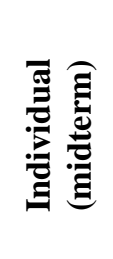 & 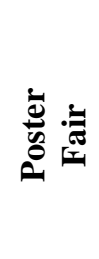 & 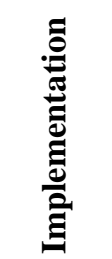 & 㞼 & 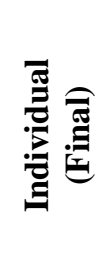 & 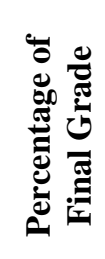 \\
\hline & $\begin{array}{c}1^{\text {st }} w k \\
\text { Oct }\end{array}$ & $\begin{array}{l}1^{\text {st }} w k \\
\text { Dec }\end{array}$ & $\begin{array}{c}2^{\text {nd }} w k \\
\text { Jan }\end{array}$ & $\begin{array}{c}2^{\text {nd }} \text { wk } \\
\text { Jan }\end{array}$ & $\begin{array}{c}1^{\text {st }} \text { wk } \\
\text { Apr }\end{array}$ & $\begin{array}{c}2^{\text {nd }} \mathrm{wk} \\
\mathrm{Apr}\end{array}$ & $\begin{array}{c}2^{\text {nd }} w k \\
\text { Apr }\end{array}$ & $\begin{array}{c}2^{\text {nd }} w k \\
\text { Apr }\end{array}$ & \\
\hline $\begin{array}{l}\text { Engineering Design: } \\
\text { Problem } \\
\text { Identification }\end{array}$ & $40 \%$ & $25 \%$ & $15 \%$ & \multirow{4}{*}{$25 \%$} & $5 \%$ & $0 \%$ & $10 \%$ & \multirow{4}{*}{$25 \%$} & \multirow{4}{*}{$49.5 \%$} \\
\hline $\begin{array}{l}\text { Engineering Design: } \\
\text { Proposed Solution }\end{array}$ & $10 \%$ & $25 \%$ & $15 \%$ & & $5 \%$ & $0 \%$ & $10 \%$ & & \\
\hline $\begin{array}{l}\text { Engineering Design: } \\
\text { Implementation }\end{array}$ & $0 \%$ & $0 \%$ & $0 \%$ & & $10 \%$ & $60 \%$ & $15 \%$ & & \\
\hline $\begin{array}{l}\text { Engineering Design: } \\
\text { Testing and/or } \\
\text { Evaluation }\end{array}$ & $0 \%$ & $0 \%$ & $0 \%$ & & $10 \%$ & $20 \%$ & $15 \%$ & & \\
\hline $\begin{array}{l}\text { Communication } \\
\text { Skills }\end{array}$ & $30 \%$ & $30 \%$ & $50 \%$ & $25 \%$ & $50 \%$ & $0 \%$ & $30 \%$ & $25 \%$ & $27.5 \%$ \\
\hline Professionalism & $10 \%$ & $10 \%$ & $10 \%$ & $25 \%$ & $10 \%$ & $10 \%$ & $10 \%$ & $25 \%$ & $11.5 \%$ \\
\hline $\begin{array}{l}\text { Individual and } \\
\text { Team Work }\end{array}$ & $10 \%$ & $10 \%$ & $10 \%$ & $25 \%$ & $10 \%$ & $10 \%$ & $10 \%$ & $25 \%$ & $11.5 \%$ \\
\hline $\begin{array}{l}\text { Percentage of Final } \\
\text { Grade }\end{array}$ & $10 \%$ & $15 \%$ & $10 \%$ & $0 \%$ & $10 \%$ & $20 \%$ & $25 \%$ & $10 \%$ & \\
\hline
\end{tabular}

process seemed fine for the project proposal but became unwieldy for the progress report. Instead of adding more and narrower indicators to accommodate unique characteristics and exceptions, broader indicators were formed in order to focus on the common fundamental elements. The original indicators were distilled into the three-to-four indicators per dimensions that are presented in Table 2. During the second term, the weights of the deliverables were also simply re-balanced, to put less weight on the proposal.

Anecdotally, the students seemed to appreciate the clear expectations. They were comfortable with their final grade being calculated from a series of marks throughout the year. The common structure, based on the engineering process, became integrated in their thinking, and they spontaneously drafted their final report along that vein. Conversations became grounded in a common vocabulary where, for instance, comparisons of design solutions or development of testing strategies were traced back to the

Table 4: Scoring Rubric for Engineering Design: Proposed Solution.

\begin{tabular}{|l|l|l|l|l|}
\hline & $\begin{array}{l}\text { Beginning } \\
\text { (Needs Work) }\end{array}$ & $\begin{array}{l}\text { Developing } \\
\text { (Satisfactory) }\end{array}$ & $\begin{array}{l}\text { Accomplished } \\
\text { (Good) }\end{array}$ & $\begin{array}{l}\text { Exemplary } \\
\text { (Excellent) }\end{array}$ \\
\hline Feasible & & & & \\
\hline Informed & & & & \\
\hline Creative & & & & \\
\hline
\end{tabular}

identified problem. In particular, the iterative nature of the engineering process became evident to the students through the continual re-visiting of all four stages in all deliverables. Problem Identification was particularly instructive because at each deliverable, the students seemed to appreciate and understand more the importance of a clearly defined, well-scoped problem definition.

Marking each deliverable does take time, especially if the habit is to simple assign a single mark, say out of 10 , with no addition formal feedback. Having a formal rubric demands a formal response, with examples taken from the students' work. We return to the title of the paper, that such feedback is a key pedagogical need. It is our opinion, as well, that the feedback is also required to use the capstone project as an effective teaching opportunity on the engineering process.

In terms of achievement, one group spent a lot time on the Project Identification, and perhaps it could be argued that their final product is not advanced as it could have been. Instead, there was a marked improvement in technical communication skills, rigorous and systematic testing, and in group dynamics. Our emphasis of formative assessment (process) over summative assessment (product) enables what we believe is an appropriate recognition of the groups execution of the engineering design process. For example, this group would have likely received a lower grade if they were judged solely on their final outputs. 


\section{FUTURE WORK}

The most pressing issue for the rubric template is the need to measure its reliability, validity and transferability. With rubrics, there is always a need to provide training (with exemplars, for instance) to develop a consistent interpretation of the achievement levels. The missing mapping function from the qualitative rubric to the quantitative marking scheme is noted.

Individual \& Team Work remains a struggle. The dimension itself adequately conveys the notion that engineers must function both as a team member, and as an individual within that team. Yet, application remains troublesome. Philosophically, the assessment instrument measures the team as a whole, but issues of fairness and practicality still need to be teased out to manage the inevitable situations where individual team members perform significantly differently. The marking scheme does attribute a portion of the grade solely to each individual, which permits some differentiation among individual team members.

We intend on including a method for including self- and peer-assessment within our assessment strategy. Reflection fits well within our concept of using assessment to adapt the learning during the project. We believe the same rubric may be appropriate for the both self- and peerassessments.

Wider adoption will require promotion and interpretation. Formative assessment may not be widely known or adopted within the engineering faculty. It will require a pedagogical shift to separate assessment of the engineering product versus the engineering process. A larger group of supervisors, and their projects, will be tested and surveyed in the coming year.

\section{CONCLUSION}

The capstone project provides experiential learning of the engineering design process. Assessment of a capstone project should measure that process learning. The project is a perfect candidate for formative assessment where each deliverable is an opportunity for an evaluation that can inform the teaching and learning in the next phase. The feedback should relate not simply to the deliverable's document or presentation but how it demonstrates the team's learning of engineering.

The compound assessment instrument presented combines both qualitative and quantitative feedback. The proposed rubrics provide learning criteria broken down into seven dimensions representing the stages of the engineering design process and their associated $\mathrm{CEAB}$ attributes. The same rubric applies to all project deliverables, but the emphasis of each dimension is tempered by weights so that the final grade assigned to that deliverable reflects the relative importance of each dimension in that deliverable.

\section{Acknowledgements}

We would like to acknowledge the participation, feedback and forbearance of the students under our supervision this year, as well as Professor Richard Dansereau who was a co-supervisor of one of the projects.

\section{References}

[1] Engineering Accreditation Commission (2011) Criteria for Accrediting Engineering Program: ABET. Available as of 2011 from

http://www.abet.org/uploadedFiles/Accreditation/Accreditation Process/Accreditation_Documents/Current/eac-criteria-20122013.pdf

[2] Engineers Canada, Canadian Engineering Accreditation Board Accreditation Criteria and Procedures 2011 : Canadian Council of Professional Engineers, 2011. Available as of May 3, 2013 from

http://www.engineerscanada.ca/files/w Accreditation Criteria P rocedures_2011.pdf on May 3, 2013.

[3] Denny Davis, Steven Beyerlein, Phillip Thompson, and Kunle Harrison, "Assessments for Three Performance Areas in Capstone Engineering Design "presented at the American Society for Engineering Education Annual Conference and Exposition, Salt Lake City, UT. 2004

[4] Robert Gerlick, Denny Davis, Steven Beyerlein, Jay McCormack, Phillip Thompson, Olakunle Harrison, Michael Trevisan, "Assessment Structure and Methodology for Design Processes and Products in Engineering Capstone Courses," American Society for Engineering Education, 2008.

[5] Alan Chong and Lisa Romkey, "Adapting Existing Assessment Tools for Use in Assessing Engineering Graduate Attributes," in Proc. CEEA Canadian Engineering Education Conf., CEEC12, Witold Kinsner (ed.) (Winnipeg, MB; 17-20 June 2012), 7 pp., 2011.

[6] David J. Nicol and \& Debra Macfarlane-Dick, "Rethinking formative assessment in HE: a theoretical model and seven principles of good feedback practice" in, C. Juwah, D. Macfarlane-Dick, B. Matthew, D. Nicol, D. \& B. Smith, Enhancing student learning though effective formative feedback. York:The Higher Education Academy, 2004.

[7] Yue Yin and Richard J.Shavelson "Formative Assessment, Motivation and Science Learning," in Handbook of Formative Assessment, Heidi L. Andrade and Gregory J. Cizek (ed.), pp.139-158, Routledge, 2010. \{ISBN: 0-415-99319-9\}

[8] SYSC4907 Engineering Project. [online] Available as of September 2012 from

https://sites.google.com/a/sce.carleton.ca/sysc-engineeringproject/ 